\title{
THE CYBER BULLYING PREVENTATIVE MEASURES
}

\begin{tabular}{|c|c|c|c|}
\hline & \multicolumn{3}{|c|}{$\begin{array}{c}\text { Dr. Jitendra Kumar Singh } \\
\text { SOMC, Sanskriti University, Mathura, Uttar Pradesh, India }\end{array}$} \\
\hline Journal & \multicolumn{3}{|c|}{$\begin{array}{l}\text { Samvakti Journal of Research in Information Technology } \\
\text { https://www.sjrit.samvaktijournals.com } \\
\text { Volume } 2 \text { Year of Volume } 2021 \text { Page No : } 109-116\end{array}$} \\
\hline Discipline & \multicolumn{3}{|l|}{ Information Security } \\
\hline Conference & \multicolumn{3}{|c|}{$\begin{array}{l}\text { A virtual international conference on redefining and transforming the role of higher } \\
\text { education in sustainable development }\end{array}$} \\
\hline Conference & \multicolumn{3}{|c|}{ Start Date: September 30, 2021} \\
\hline Dates & \multicolumn{3}{|c|}{ End Date : September 30, 2021} \\
\hline Institute Name & \multicolumn{3}{|c|}{$\begin{array}{l}\text { JAIN (Deemed-to-be University) in association with Council for Industrial } \\
\text { Innovation and Research }\end{array}$} \\
\hline $\begin{array}{l}\text { Date Received } \\
\text { ID } \\
\text { Dol }\end{array}$ & $\begin{array}{l}\text { : November } 19,2021 \\
: 2021.02 .23 \\
: 10.46402 / 2021.02 .23\end{array}$ & $\begin{array}{l}\text { Publication Date } \\
\text { Paper Type } \\
\text { Dol URL }\end{array}$ & $\begin{array}{l}\text { : December 11, } 2021 \\
\text { : Conference Paper } \\
\text { : https://dx.doi.org/10.46402/2021.02.23 }\end{array}$ \\
\hline
\end{tabular}

\section{ABSTRACT}

Students' impressions of the efficacy of various harassment prevention measures were studied in this research. According to the results, the data was gathered via a countrywide electronic survey of teenagers. Depending on individual relationships with cybercrime, the 713 adolescents who replied to all 39 questionnaire study were divided into 4 teams: pure attacker, pure victims, both perpetrator and complainant, because both perpetrator and victims. It looks at the link of both a participant's involvement in harassment and their opinion of how good a guidance and counseling strategy is. The five most successful harassment mitigation measures for adolescents are examined and rated independently from each of the 4 areas. Irrespective about where they feel on the subject of harassment, teenagers think that shutting off the suspect's access to the information is by far the more successful method, according with results of this survey. The findings of this research may be helpful in the development of policies and laws to successfully reduce cyberbullying in schools and communities.

KEYWORDS: Adolescents, Bullying, Cyber Bullying, Harassment, Victim. 


\section{INTRODUCTION}

Technical breakthroughs have represents a novel age of harassing involved in online abuse in the 21st centuries. The rise in the prevalence of harassment during 2000 and 2005 , and even the amount of cases taken to justice, demonstrate that institutions are illequipped to cope with the problem. Many dangerous incidents of cybercrime occurs off campuses, leaving it challenging for education institutions to punish a youngster for expressing their rights to creative speech while stepping over the border into intimidation. It is a challenge for schools to come up with effective cyber bullying prevention methods. Kids may perceive different methods for halting and preventing cyberbullying than adults do, and the strategies adults deem successful may not be the same as the ones students perceive to be helpful.

Student bullies and victims are not often identified, nor are they branded as such. It is possible to distinguish them as bullies as well as victims in certain situations. When bullied, victims may frighten younger children or react by engaging in cyberbullying. It has not been reported that any pupils have been bullied or cyber bullied. The phenomenon of cyberbullying has been extensively studied in recent years, although the term used in various research has changed considerably. This has a significant effect on findings in certain cases, and since it is difficult to achieve agreement, the "definition" is still being disputed by academics all over the globe today ${ }^{[1]}$.

Cyber stalking is a phrase that relates to a range of harassing practices that involve the violent and purposeful use of technological equipment namely the smartphones to damage someone range of human beings. Like "traditional" harassment, cybercrime is defined by a history of repetitive behavior and a control differential seen among attacker and the sufferer." All of these classifications highlight purpose, persistence, and power dynamics, which, contrary with research, are the most fundamental differentiating elements of harassment.

If such characteristics are available, we may speak regarding interpersonal harassment; nevertheless, due to the obvious opportunities afforded by the online ecosystem, the assailant has an even better chance of contacting the victims than in traditional physical situations. As a result, investigators distinguish among explicit harassment (which is much more widespread and the subject of the latest study) and indirectly harassment. The situation in where somebody else performs the "dirty work" for the aggressive, such as an administration who removes the perpetrator's page that after perpetrator complains it, or a client who complains the attacker to the administration, is an example of vicarious harassment. Individuals who are utilized as the initiator in an online harassment situation are typically ignorant that there are having used in this way, which is also the basic 
definition of the term keyboard warrior. Because adults are often unknowingly engaged in it, it is regarded to be hazardous ${ }^{[2]}$.

\section{Cyberbullying:}

Cyberbullying is an issue that continues to plague young people all over the globe today. As a consequence of being harassed by cyberbullying, some teenagers suffer from despair, have their educational opportunities hampered, and even commit suicide as a result of the issue. Scholars conducted an analysis of 1,500 adolescents and discovered that 33 percent of those who responded had been victims of cyberbullying.

The demographic subgroup that faced the most incidences of cybercrime was women here within aged of 15 and 16 . Since 2000 , according to a study published by the University of New Hampshire in 2005, there has been a rise in the frequency of cyberbullying. According to a study conducted in May 2009, two-thirds of the teenagers polled believed that cyberbullying was a significant problem.

\section{Relationship Between Bullying and Cyberbullying:}

If a kid is being harassed at school, he or she may also be tormented online. Additionally, cyberbullying and traditional bullying are intertwined. As per results of a research, over about a half of the 12-15 year old volunteers who'd been abused digitally have also been assaulted at classroom. They showed that "harassment and retribution internet and in the classrooms" had a substantial link.

An online bully may be a kid who has been tormented at school in order to revenge against the bullying that has taken place there. Bullying and cyberbullying may occur as distinct incidents, whereas bullying and cyberbullying can be intertwined with one another. Victims of cyberbullying are not always the same as those who are bullied in school. Following the publication of their research ${ }^{[3]}$.

Because the use of technology is not regulated on campus, many bad instances of cyber bullying occur outside from the school setting. Off-campus harassment has really been demonstrated to have a detrimental influence on the educational atmosphere, create difficulties for sufferers to concentrate in schools, raise the risk of suffering psychiatric disorders, and put children' security at risk. Schools may be involved in online activities that take place outside from the school grounds, which might result in acts such as school violence. Students may be agitated when they arrive at school as a consequence of disagreements that have erupted via internet contact.

A pupil will not be aware of what has been written about him or her online until the following day when he or she hears about it at school. Being angry over an instance of cyberbullying while at school may make it difficult for a kid to concentrate on his or her 
academics while at school. Universities are hesitant to punish children for cybercrime that occurs off campuses since officials fear becoming brought liable for infringing on a person's First Constitution principle of free expression. And pursuant to academic, a person's come up short conduct would only be penalized if it "substantively disrupts" schoolwork or "seriously conflicts with both the freedom of everyone else"[4].

Online abuse is generally seen to become greater severe than conventional harassing since it happens $24 / 7$ per day, 7 days a week have a limitless viewership. Technologies enables knowledge to be sent to a huge quantity of individuals in a small period of time. Technologies will spread rumors and embarrassing photos more quickly and to a larger audience than networking ever would have. When electronics is used rather of recommendations from friends, everybody receives this really identical messages. The rumors will continue to circulate indefinitely on the Internet.

\section{Bullying Prevention Techniques:}

Increased levels of school violence throughout the 1990s prompted schools to implement anti-bullying policies to combat the problem. The National Security agency and the Ministry of Agriculture looked into 37 "occurrences of planned youth crime" that had been disclosed to police during 1974 and June 2000. Concern should be expressed about a study that found "almost three-quarters of the assailants had been harassed, bullied, intimidated, assaulted, or wounded by others previous to the event." The assailants "reported being bullied," in language that suggested that these interactions were on the verge of becoming torture.

Bullying was found to have had a part in the perpetrator's determination to carry out the brutal assault at his former school, according to the investigation. Schools have created programmes to deal with the issues of school violence and bullying, which have become widespread. Whenever it came to cyberbullying avoidance, the most successful strategies focus on altering the classroom atmosphere to establish a negative atmosphere that encourages harassment. The introduction of explicit regulations and consequences, the incorporation of behavioral interventions into the curricula, familial engagement, and rehabilitation programs for extremists and oppressors' targets were all part of the international Victimization cyberbullying avoidance plan ${ }^{[5]}$.

In Norwegian, this approach also seems to be helpful, but that has not had the same effectiveness in the U.S. The Olweus harassment reduction project's findings have yet to be reproduced in another location. It's thought that the Olweus harassment preventive program's effectiveness stems from the premise that this was implemented in classrooms after fatalities connected to cyberbullying were made apparent. The Olweus bullying prevention initiative was developed by the University of Minnesota. Considering that the total reduction in bullying occurrences has been about 15 percent, anti-bullying measures 
have been only somewhat successful so far. When it comes to bullying, onlookers are the target audience. Bullying ends in 57 percent of cases when a bystander intervenes in a bullying event within ten seconds, according to the research of Hawkins, Pepler, and Craig (see Resources). The success of a bullying programme may be evaluated by the choice of a bystander to intervene or encourage bullying ${ }^{[6]}$.

\section{Laws Against Cyber Bullying:}

Electronics communications is described as the transfer of any writing, audible, or graphical material via an electrical appliance, such as a smartphone, cellphone, and another modern communications handset, and perhaps a laptop. In accordance with state anti-bullying prevention statutes, schools are required to establish anti-bullying policies. These policies may contain provisions for dealing with cyberbullying, educational programmes, and reporting procedures. The state of Colorado has comprehensive programme requirements for Internet safety education, which are followed by other states $^{[7]}$.

\section{DISCUSSION}

Victims of cyberbullying exhibit a wide range of responses when confronted with a distressing circumstance from which it is sometimes impossible to extricate themselves. Namely, the researchers looked at victims' responses to online harassment, specifically the occurrence of various in the context of internet harassing, sufferers' feelings and subsequent behavior are discussed. Anger, sorrow, worry, humiliation, weeping, fear, and self-blame were some of the feelings experienced by the participants. Other consequences were found, including decreased attention and school grades, as well as absenteeism from school.

The researchers therefore inclined to link this to the concept of interpersonal domination, wherein the sufferers perceive they will be in a subordinate situation to the perpetrator, which produces unpleasant feelings in the victims and has an impact on their behaviour in the school setting. According to the authors, a large number of respondents said that they had not been subjected to online harassment. Because harassment is seen as "normal" or "expected," the authors hypothesized that this was the case.

In connection with cyberbullying - for example, according to a study - the vast majority of victims displayed symptoms of stress, which was caused by the bullying. From a therapeutic standpoint, the victims displayed internalized symptoms, loneliness and poor self-esteem that were linked to externalization, as well as general difficulties (both emotional and behavioral). Among the aggressive acts were: obtaining smartphone images of the offenders recorded against your consent; shaming or humiliating the sufferer's digital; cruel messages from friends, disrespectful, physically suggestive 
messages from colleagues, letters frightening sufferers with personal injury; and digital falsehoods or accusations about just the perpetrators.

Individuals who are subjected to this combination become victims on a worldwide scale. In the case of individuals who have been victimized in a variety of methods and settings, there is a greater likelihood of an outbreak of severe stress. As a result of double bullying, researchers have discovered a wide variety of issues in victims, including social problems, behavioral problems, the impression that they are being evaluated negatively by their peers, poor self-esteem, and loneliness. Scholars investigated the emotional responses of teenagers to cyberbullying based on the different forms of cyberbullying that they observed. Among those who have been bullied, the most common emotions experienced were anger (10.3 percent), sorrow (4.9 percent), disinterest in school (3.6 percent), and disillusionment with and mistrust of classmates (2.9 percent).

When victims are cyberbullied, they are accessible at all times, because there is never a moment where sms texts, letters, or any other forms of communication can indeed be delivered; the behaviors of teenagers when they came across touch with outsiders are also handled indirectly - Online harassment by an adults the same or opposing genders, a strangers, or a group of individuals causes sufferers to experience dread, which may lead to actual or death, according to the research. The reason for this is because, as compared to cyberbullying by the victim's peers, there is a far greater imbalance of power.

Cyberbullying, like conventional bullying, has been linked to a broad variety of mental and psychosomatic disorders, according to research. Teenage survivors who did not emerge out of a 2 relatives had more psychophysiological troubles, such as migraine, snooze disturbances, and repetitive abdomen pains; a greater amount of apparent issues; sentimental and participant troubles; and a feeling of insecurity at university and then being overlooked by educators, between some out of more items. In additional to the other features mentioned in the research, childhood and adolescence displayed signs of excitability, repeated nicotine, drinking, and a low level of constructive socialization behavior.

The researchers looked at individuals' encounters with perpetration and victimization in the 30 days leading up to the survey. Abuse perpetrators and sufferers were both addressed. The authors looked at the connections between any of these occurrences and suicide thoughts and action. Toddlers and teens who had been sufferers or perpetrators of traditional harassment or harassment had greater degrees of depressive thoughts but were most likely to have depression than someone who has not. Victimhood, rather than misbehaving, was said to be a greater predictive of suicide attitudes and behaviour.

As per a survey of school abuse that also looked at the effects of cyber-attack, more invariably and cited unfavorable repercussions were sufferers' self-esteem (78\%), 
identity ( $70 \%)$, and companionship. 35 percent of those who answered the survey said it had a bad effect on their school grades, 28 percent said it had a negative impact on their school attendance, and 19 percent said it had a negative impact on their family ties. Many of the respondents said that it had a significant effect on their emotional behaviour. Seventy-five percent of those who answered the survey expressed sorrow, with 54 percent describing emotions of severe sadness. Furthermore, 58 percent reported feeling angry, 48 percent reported feeling humiliated, and 48 percent reported feeling dread, with 29 percent reporting feeling scared. Three percent were contemplating suicide, and two percent had self-harmed as a result of cyberbullying.

\section{CONCLUSION}

First and foremost, the offenders are the kind of pupils who should be discouraged by intervention methods. According to the statistics, the specific remedy that the offenders found to be effective was a penalty that restricted their ability to use the internet and other technological resources. In general, the offenders were considered effective because they followed consistent regulations and enforced penalties, as well as because they participated in continuing preventative initiatives. First and foremost, regardless of their views on cyberbullying, adolescents saw the topic of limiting the offender's access to technology as a very effective preventative measure. Due to the fact that all teenagers are members of a generation that engages in cyber immersion, regardless of their views on cyber bullying, this outcome is understandable. The term "cyber immersion" refers to the fact that the Internet serves as the main method of communication for people in terms of relationships, commerce, and leisure. Teenagers may experience a loss of their main method of communication and a sense of alienation if they are denied access to the Internet and technology. The possession of one's own mobile phone and gadget is considered a prize possession among teenagers, regardless of their views on cyberbullying. 


\section{REFERENCES}

[1] P. W. Agatston, R. Kowalski, and S. Limber, "Students' Perspectives on Cyber Bullying," Journal of Adolescent Health. 2007, doi: 10.1016/j.jadohealth.2007.09.003.

[2] T. Y. Bingöl, "Determining the predictors of self-efficacy and cyber bullying," Int. J. High. Educ., 2018, doi: 10.5430/ijhe.v7n2p138.

[3] K. L. Modecki, J. Minchin, A. G. Harbaugh, N. G. Guerra, and K. C. Runions, "Bullying prevalence across contexts: A meta-analysis measuring cyber and traditional bullying," Journal of Adolescent Health. 2014, doi: 10.1016/j.jadohealth.2014.06.007.

[4] L. R. Betts, K. A. Spenser, and S. E. Gardner, "Adolescents' Involvement in Cyber Bullying and Perceptions of School: The Importance of Perceived Peer Acceptance for Female Adolescents," Sex Roles, 2017, doi: 10.1007/s11199-017-0742-2.

[5] K. Ozansoy, Z. Altinay, and F. Altinay, "Developing strategies to prevent "cyberbullying,"' Eurasia J. Math. Sci. Technol. Educ., 2018, doi: 10.29333/ejmste/85499.

[6] N. Antoniadou, C. M. Kokkinos, and A. Markos, "Possible common correlates between bullying and cyber-bullying among adolescents," Psicol. Educ., 2016, doi: 10.1016/j.pse.2016.01.003.

[7] F. Mishna, M. Khoury-Kassabri, T. Gadalla, and J. Daciuk, "Risk factors for involvement in cyber bullying: Victims, bullies and bully-victims," Child. Youth Serv. Rev., 2012, doi: 10.1016/j.childyouth.2011.08.032. 